\title{
Microbiota intestinal y cáncer
}

\author{
Gastrointestinal microbiota and cancer \\ Microbiota intestinal e câncer
}

\author{
Dolores Rodríguez Veintimilla', Evelyn Frías Toral ${ }^{2 *}$
}

Recibido: 1 de julio de 2020. Aceptado para publicación: 23 de septiembre de 2020

Publicado en línea: 22 de octubre de 2020

https://doi.org/10.35454/rncm.v4n1.175

\begin{abstract}
Resumen
La microbiota es el conjunto de microorganismos localizado en diferentes sitios del cuerpo. Aquellos que se encuentran en el intestino tienen un rol esencial, debido a la estrecha relación que tienen con la salud y la enfermedad, en especial el cáncer. Conocer qué microorganismos pueblan el tracto gastrointestinal y sus funciones, qué ocurre cuando se altera su composición, así como identificar su relación con una microbiota saludable para la prevención del desarrollo de tumores, o cómo se vincula la alteración de la microbiota con el desarrollo de tumores merece especial atención. La microbiota intestinal se vislumbra como una pieza clave en el tratamiento del cáncer. El objetivo de la presente revisión es definir el modo en que los microorganismos intestinales pueden influir profundamente en la potencia de la inmunoterapia y de algunas quimioterapias, y conocer de qué forma pueden contribuir también a repoblar la flora intestinal afectada por los tratamientos oncológicos, preguntas que ameritan una revisión extensa de las publicaciones al respecto.
\end{abstract}

Palabras clave: microbiota, cáncer, salud, enfermedad.

\section{Abstract}

Microbiota is defined as the group of microorganisms present in several places in the body. Those found in the intestine play an essential role due to the close relationship they have with health and disease, and particularly with cancer. Knowing which microorganisms populate the gastrointestinal tract, their functions, the effects of altering their composition, as well as identifying the relationship between a healthy microbiota and the prevention of tumor development, or how its alteration is linked to tumor development, deserves special attention. The gut microbiota is perceived as a key element piece in the treatment of cancer. The objective of this review is to define how intestinal microorganisms can profoundly influence the effectiveness of immunotherapy and some chemotherapies, and to understand how they can also contribute to repopulate the gut flora affected by cancer treatments. These questions deserve an extensive review of published data.

Keywords: Gastrointestinal microbiota; Cancer; Health; Disease.

\section{Resumo}

A microbiota é o conjunto de microrganismos localizados em diferentes partes do corpo. Aqueles que estão no intestino têm um papel essencial, devido à estreita relação que mantêm com a saúde e a doença, principalmente o câncer. Saber quais microrganismos habitam o trato gastrointestinal, suas funções, o que acontece quando sua composição é alterada, bem como identificar sua relação com uma microbiota saudável para a prevenção do desenvolvimento de tumores, ou como sua alteração está ligada ao desenvolvimento dos mesmos, merece atenção especial.

A microbiota intestinal é vista como um elemento chave no tratamento do câncer. O objetivo desta revisão é definir como os microrganismos intestinais podem influenciar profundamente na potência da inmunoterapia e de algumas quimioterapias e saber como eles também podem contribuir para repovoar a flora intestinal afetada pelos tratamentos oncológicos, questões que merecem uma extensa revisão das publicações a respeito.

Palavras-chave: microbiota intestinal, câncer, saúde, enfermidade.
Servicio de Nutrición Clínica y Metabolismo, Sociedad de Lucha Contra el Cáncer. Guayaquil, Ecuador.
2 Comité de Investigación, Sociedad de Lucha Contra el Cáncer. Universidad Católica Santiago de Guayaquil, Guayaquil, Ecuador.

*Correspondencia: Evelyn Frías Toral

evelyn.frias@cu.ucsg.edu.ec 


\section{INTRODUCCIÓN}

Conocer la estrecha relación entre el ser humano y los microorganismos que habitan en él es de suma importancia para comprender cómo se puede alterar la salud cuando este equilibrio se ve afectado. En la actualidad, no se denominan a estos seres vivos "flora intestinal" ni se consideran simplemente comensales, estimando que los seres humanos son, de hecho, "superorganismos" gobernados, en parte, por los microorganismos que hospedan ${ }^{(1)}$.

El término "microbiota" hace referencia a la comunidad de microorganismos vivos residentes en un nicho ecológico determinado ${ }^{(2)}$. La microbiota residente en el intestino humano es una de las comunidades más densamente pobladas; en el colon de los mamíferos, la cifra de microorganismos se eleva entre $10^{12}$ y $10^{14}$. Esta cifra es mayor que el número de células humanas ${ }^{(3)}$.

Por su parte, el cáncer es una enfermedad multifactorial que representa la segunda causa de muerte a nivel mundial ${ }^{(4)}$. Se plantea que este resulta de la acumulación intracelular de mutaciones espontáneas durante la replicación del ácido desoxirribonucleico (ADN), combinada con la exposición al medio ambiente y los hábitos de estilo de vida, ambos capaces de influir significativamente en el riesgo de desarrollar cáncer ${ }^{(5)}$.

En los últimos años, numerosas evidencias han apuntado hacia el papel central de las bacterias comensales, que cuando colonizan las superficies del cuerpo son determinantes clave para la salud y para afecciones patológicas, incluido el cáncer ${ }^{(6)}$. De las patologías ligadas con el microbioma intestinal, la tumorigénesis es una de las más estudiadas. Es importante destacar que este vínculo ha sido encontrado tanto para cáncer de localización gastrointestinal como para tumores distales ${ }^{(7)}$.

Se realizó una búsqueda de la literatura publicada en PubMed usando terminología MeSH relacionada con microbiota intestinal y cáncer empleando operadores booleanos. Se escogieron artículos tanto en inglés como en español publicados entre los años 2010 y 2020. El objetivo de la presente revisión es establecer la relación entre la microbiota intestinal y el cáncer, para determinar su influencia en el desarrollo y tratamiento de algunas patologías oncológicas.

En la Tabla 1 se encuentran los conceptos en relación con la microbiota con la finalidad de tener mayor comprensión del tema ${ }^{(8)}$.

\section{MICROBIOTA INTESTINAL}

Está compuesta por diversidad de microorganismos como bacterias, hongos, arqueas, virus y protozoos.
Tabla 1. Conceptos clave en la literatura de la microbiota

Microbioma humano: es el conjunto formado por los microorganismos, sus genes y sus metabolitos que colonizan el cuerpo humano.

Metagenoma: corresponde al material genético del microbioma y del hospedero.

Metagenómica: estudio de una colección del material genético de las bacterias directamente de una muestra del medio en estudio.

Metatranscriptómica: estudio del ARN total transcrito.

Metaproteómica: estudio de las proteínas.

Metabolómica: estudio de los perfiles metabólicos.

ARN: ácido ribonucleico.

Entre los individuos a nivel de filo (principalmente Bacteroidetes y Firmicutes), la composición del microbioma intestinal es semejante y se encuentran variantes en relación con la diversidad y población de las especies. La genética del huésped, los factores ambientales, la dieta, la enfermedad, el estrés y algunos otros factores deciden la estructura de la microbiota intestinal ${ }^{(9)}$.

Es importante prestar mucha atención al impacto de la microbiota intestinal en algunos tipos de cáncer como los de colon, hígado y mama, y su impacto en la eficacia de la quimioterapia e inmunoterapia contra el cáncer ${ }^{(10)}$. Sin embargo, la Declaración internacional del consenso de expertos en microbioma y cáncer considera que, a pesar de la evidencia mecanicista y de apoyo de estudios en animales y humanos, actualmente no hay evidencia directa de que el microbioma comensal humano sea un determinante clave en la etiopatogenia del cáncer. El panel citó la falta de grandes estudios de cohorte longitudinales como un factor decisivo principal y acordó que esta debería ser una prioridad de investigación futura ${ }^{(11)}$.

La colonización del tracto intestinal del neonato inicia desde el nacimiento, creando finalmente un microambiente rico y diverso. La microbiota se adquiere en el canal de parto y, luego, a través de la leche materna. Los perfiles microbianos fecales de los lactantes muestran una gran similitud con los perfiles bacterianos maternos vaginales y de la leche materna ${ }^{(12,13)}$. Es por ello que al pasar por el canal vaginal adquieren la microbiota de la madre, Lactobacillus, Prevotella y Sneathia spp. Aunque solo algunos de estos colonizadores permanecerán en los lactantes, la exposición inicial es un punto clave para el desarrollo de la microbiota adulta. En aquellos recién 
nacidos por cesárea, las principales bacterias colonizadoras son del tipo Staphylococcus, Corynebacterium y Propionibacterium spp, que se originan en la microbiota de la piel de la madre ${ }^{(14)}$.

Con la cesárea hay una alteración de la transmisión vertical de la microbiota de madre a hijo y en los niños nacidos por esta vía se ha observado predisposición al desarrollo de una serie de enfermedades de tipo inflamatorio, autoinmunitario y metabólico, tales como asma, diabetes, obesidad y enfermedades gastrointestinales crónicas ${ }^{(15,16)}$.

Se estimaba que durante la vida intrauterina el feto estaba completamente desprovisto de microbiota. Sin embargo, hay datos que muestran indicios de su presencia en el líquido amniótico, cordón umbilical y placenta sin estar asociados con procesos infecciosos ${ }^{(12)}$.

Durante el curso de la primera infancia, la composición microbiana cambia con la edad y la dieta ${ }^{(9)}$. Desde el punto de vista evolutivo, el carácter de la microbiota intestinal depende en gran medida de la fuente nutricional principal, separando los perfiles bacterianos de omnívoros, carnívoros y herbívoros ${ }^{(17)}$.

La microbiota intestinal cumple con numerosas funciones vitales, incluidas la producción de vitaminas, metabolización de compuestos de la dieta, protección contra la infiltración y expansión sistémica de patógenos intestinales ${ }^{(8)}$.

A las alteraciones de la microbiota intestinal y la respuesta adversa del hospedero se le ha denominado "disbiosis"(18). Esta se asocia con afecciones tan disímiles como el asma, enfermedades inflamatorias crónicas, obesidad $^{(19,20)}$, esteatosis hepática no alcohólica ${ }^{(21)}$, diabetes mellitus ${ }^{(22)}$, enfermedades cardiovasculares ${ }^{(23)}$ y cáncer ${ }^{(7)}$. Allí radica precisamente la importancia de cuidar de la microbiota con la finalidad de prevenir estas enfermedades crónicas que afectan a gran parte de la población mundial.

Resulta importante conocer el tipo de bacterias, su concentración, ubicación y acción para una comprensión integral de patologías asociadas con disbiosis en esos segmentos (Tabla 2).

El intestino está conectado bidireccionalmente con el sistema nervioso a través del llamado "eje intestinocerebro" (EIC), que incluye el sistema nervioso central (SNC), el sistema nervioso autónomo (SNA), el sistema nervioso entérico (SNE), el eje hipotalámico pituitario suprarrenal (EHP) y el sistema enteroendocrino (SEE). Las hormonas y las neurohormonas secretadas en cada uno de estos niveles de EIC enumerados pueden modular las actividades digestivas y metabólicas gastrointestinales, y viceversa ${ }^{(23)}$.

Por esa razón, el intestino representa una interfaz compleja entre la microbiota gastrointestinal residente y el cuerpo humano. Existe una relación bidireccional entre los microbios residentes intestinales y el EIC del huésped, en el que el intestino funciona como el portero de la comunicación ${ }^{(24,25)}$. En particular, se sabe que las hormonas y las neurohormonas del huésped pueden

Tabla 2. Bacterias comunes encontradas en diferentes localizaciones, con respectivas concentraciones bacterianas, funciones intestinales principales y los valores de $\mathrm{pH}$ encontrados a lo largo del tracto gastrointestinal ${ }^{(1)}$

\begin{tabular}{|c|c|c|c|}
\hline Bacterias & Localización & Concentración (UFC/mL) & Función del pH \\
\hline $\begin{array}{l}\text { Lactobacillus } \\
\text { Streptococcus } \\
\text { Helicobacter } \\
\text { Peptostreptococcus }\end{array}$ & Estómago & $1 \times 10^{2}$ & $\begin{array}{l}\text { Secreción de }(\mathrm{HCl}) \\
\text { Digestión de macromoléculas } \\
\mathrm{pH} 2\end{array}$ \\
\hline $\begin{array}{l}\text { Streptococcus } \\
\text { Lactobacillus }\end{array}$ & $\begin{array}{l}\text { Duodeno } \\
\text { Yeyuno } \\
\text { Íleon }\end{array}$ & $10^{1}$ a $10^{3}$ & $\begin{array}{l}\text { Digestión y absorción de monosacáridos, } \\
\text { aminoácidos, ácidos grasos y agua } \\
\text { pH 4-5 }\end{array}$ \\
\hline $\begin{array}{l}\text { Bacteroides } \\
\text { Clostridium } \\
\text { Streptococcus } \\
\text { Actinomyces }\end{array}$ & $\begin{array}{l}\text { Ciego } \\
\text { Colon proximal }\end{array}$ & $10^{11}-10^{12}$ & $\begin{array}{l}\text { Ácidos biliares } \\
\text { Vitamina B12 } \\
\text { Absorción de agua } \\
\text { pH } 7\end{array}$ \\
\hline $\begin{array}{l}\text { Bacteroides } \\
\text { Clostridium } \\
\text { Streptococcus } \\
\text { Actinomyces }\end{array}$ & Colon distal & $10^{11}-10^{12}$ & $\begin{array}{l}\text { Ácidos biliares } \\
\text { Vitamina B12 } \\
\text { Absorción de agua } \\
\text { pH } 7\end{array}$ \\
\hline
\end{tabular}

$\mathrm{HCl}$ ácido clorhídrico; UFC: unidad formadora de colonias. Fuente: Modificado de ${ }^{(1)}$. 
modificar la composición del microbioma intestinal, como durante la respuesta al estrés. Es importante destacar que las células gastrointestinales enteroendocrinas secretan más de 30 hormonas peptídicas diferentes, involucradas en varias funciones, como la motilidad gastrointestinal, las funciones digestivas y la neuromodulación. Las bacterias intestinales a su vez pueden detectar varias de estas hormonas, como en el caso de la leptina y la grelina, que complementan finamente la composición de la microbiota intestinal en los roedores ${ }^{(26)}$.

\section{INFLAMACIÓN Y CÁNCER}

Hace más de 150 años, R. Virchow hizo la primera conexión entre inflamación y cáncer al observar leucocitos en tejidos neoplásicos ${ }^{(27)}$. Recientemente, se ha obtenido evidencia de un mecanismo molecular subyacente que sugiere que la inflamación juega un papel importante en la tumorigénesis y que la inflamación crónica aumenta el riesgo de cáncer ${ }^{(28,29)}$. Hasta el $10 \%$ al $20 \%$ de todos los cánceres pueden atribuirse a infecciones, a menudo crónicas. En términos de desarrollo más generales, hasta el $20 \%$ de todos los cánceres están precedidos por inflamación crónica en el sitio del cáncer, como lo ejemplifican el carcinoma hepatocelular (CHC), el cáncer de colon (CAC), la enfermedad inflamatoria intestinal (EII), el cáncer gástrico y gastritis inducida por Helicobacter pylori ${ }^{(30)}$. Sin embargo, el papel de la inflamación no se limita a su acción durante el inicio y crecimiento del tumor, esta también se puede inducir en el crecimiento del tumor (inflamación provocada por el tumor) o como respuesta a la terapia anticancerígena y la muerte celular ${ }^{(31)}$.

\section{DE LA MICROBIOTA A LA PROGRESIÓN DEL CÁNCER}

Conviene formular estas preguntas: ¿cómo los microbios promueven el desarrollo y progresión del cáncer?, ¿estos dan inicio a un microambiente protumorigénico o aparecen como resultado del cáncer? Presumiblemente, la respuesta se encuentra en algún lugar, en medio de las investigaciones realizadas. Una característica común en muchas enfermedades en las que la microbiota contribuye a la progresión es la interrupción de las capas mucosas/epiteliales de los órganos, lo que facilita que las bacterias (o productos bacterianos y sus metabolitos) pasen a los compartimentos que normalmente no están cerca de los microbios. Esto puede desencadenar una respuesta inflamatoria crónica local, debido al tejido perpetuamente lesionado y, por tanto, a una corriente constante de microbios infiltrantes/productos microbianos. Por ejemplo, en la EII y el cáncer colorrectal (CCR), la barrera mucosa subyacente se rompe, ya sea por defecto genético o por la rápida expansión de las células tumorales, exponiendo el tejido del colon y las células inmunes residentes a grandes cantidades de antígenos y productos microbianos $^{(30)}$.

\section{DISBIOSIS Y CARCINOGÉNESIS}

La disbiosis puede ser causada no solo por organismos patógenos y comensales de los portadores, sino también por el envejecimiento y factores ambientales como el uso de antibióticos, xenobióticos, tabaquismo, ciertas hormonas y señales dietéticas. Estos también son factores de riesgo bien establecidos para el desarrollo de neoplasias intestinales o extraintestinales. Además, los defectos genéticos que afectan los componentes epiteliales, mieloides o linfoides del sistema inmunitario intestinal favorecen la disbiosis porque promueven estados inflamatorios que aumentan el riesgo de transformación neoplásica del huésped, como la enfermedad de Crohn. Por tanto, varios factores que favorecen la carcinogénesis también promueven la disbiosis ${ }^{(32)}$.

Los estudios epidemiológicos que vinculan las infecciones intraabdominales, el uso de antibióticos o ambos a una mayor incidencia de $\mathrm{CCR}^{(32)}$ subrayan la importancia clínica de la asociación entre la disbiosis y la carcinogénesis intestinal. De hecho, la microbiota intestinal afecta la carcinogénesis colorrectal por diversos mecanismos. Anular o alterar específicamente la composición de la microbiota intestinal influye en la incidencia y progresión del CCR en modelos de tumorigénesis tanto genéticos como carcinógenos ${ }^{(33)}$. Además, varios subproductos de la microbiota intestinal se dirigen específicamente a las células epiteliales intestinales (CEI) y median los efectos oncogénicos (como se informó para el sulfuro de hidrógeno y la toxina Bacteroides fragilis) ${ }^{(34)}$, o suprimen la tumorigénesis (como se demostró para los ácidos grasos de cadena corta) ${ }^{(35)}$.

Los microbios intestinales participan en algo más que la carcinogénesis colorrectal. Las alteraciones experimentales de la microbiota intestinal han mostrado que también influyen en la incidencia y progresión de los cánceres extraintestinales, incluido el carcinoma de mama y hepatocelular, presumiblemente a través de circuitos inflamatorios y metabólicos ${ }^{(36)}$. Estos resultados son compatibles con los hallazgos de los estudios 
epidemiológicos que revelan una asociación entre la disbiosis, sus consecuencias o determinantes (en particular, el uso excesivo de antibióticos) y una mayor incidencia de neoplasias extracolónicas, incluido el carcinoma de mama ${ }^{(31)}$.

Entonces, debe considerarse a la microbiota intestinal en un doble rol: en el primero, puede actuar como promotor de tumores asociado con disbiosis; y en el segundo, como supresor de tumores.

\section{MICROBIOTA INTESTINAL COMO PROMOTOR DE TUMORES}

Con respecto al cáncer, dentro de un intestino disbiótico, ciertos patógenos bacterianos pueden afectar negativamente el metabolismo del huésped o las funcionalidades del sistema inmunitario y del intestino, lo que desencadena el crecimiento del tumor ${ }^{(37)}$. Es importante destacar que la disbiosis gastrointestinal se ha relacionado con tumores locales y distantes. Se sabe que los patógenos microbianos controlan el $20 \%$ de la tumorigénesis y un mayor número de neoplasias están asociadas con un desequilibrio comensal microbiano o disbiosis ${ }^{(35)}$. En consonancia con lo anterior, muchos estudios preclínicos realizados con modelos de ratones libres de gérmenes demostraron la forma en que el microbioma intestinal puede afectar profundamente la génesis y la progresión del cáncer a través de diferentes mecanismos $^{(38)}$.

Un ejemplo a considerar es el $H$. pylori, que produce la proteína CagA y esta fue la primera proteína que demostró su relación con un cáncer humano, estableciendo que el $H$. pylori es considerado un carcinógeno tipo I por la Organización Mundial de la Salud (OMS). De hecho, durante las infecciones patogénicas, cuando el microbioma intestinal se ve afectado por la disbiosis, los patógenos bacterianos pueden expandirse y liberar una gran cantidad de toxinas, las cuales inducen la ruptura del ADN del huésped, lo que contribuye a la inestabilidad genómica, el inicio del tumor y la progresión en las células predispuestas ${ }^{(39)}$. Este es el caso de la colibactina y la toxina distendida del citoletal (CDT), producidas por Escherichia coli y que muestran una actividad de desoxirribonucleasa (ADNsa). Estas sustancias, una vez liberadas en la proximidad del epitelio gastrointestinal, generan rupturas de la doble cadena de ADN dentro de las células epiteliales del huésped, lo que promueve una detención transitoria del ciclo celular, permite que surjan mutaciones genómicas y, finalmente, conduce a la formación de tumores ${ }^{(40)}$. Las bacterias patógenas intestinales también pueden interferir con la respuesta al daño del $\mathrm{ADN}$ y reparar las vías, como en el caso de Shigella flexneri, mediante la inducción de la degradación de p 53 de las células del huésped a través de la secreción de sus enzimas inositol fosfato fosfatasa D ( IpgD) y el gen de virulencia tipo cisteína proteasa A (VirA); por tanto, aumenta la probabilidad de introducir mutaciones durante la respuesta al daño del ADN en las células infectadas ${ }^{(41)}$.

\section{MICROBIOTA INTESTINAL COMO SUPRESOR DE TUMORES}

Sorprendentemente, varias moléculas derivadas de los microorganismos muestran una actividad antitumoral; en particular, los ácidos grasos de cadena corta pueden tener un efecto anticancerígeno. Por ejemplo, el butirato y el propionato pueden inhibir las histonas desacetilasas de las células tumorales del huésped con un efecto anticancerígeno, siendo este mecanismo la causa del efecto antitumoral in vitro e in vivo del butirato observado tanto en CCR como en linfoma ${ }^{(42)}$.

Algunas de las moléculas y los metabolitos derivados de los probióticos pueden modificar el sistema inmunitario del huésped, lo que desencadena un efecto indirecto como una respuesta inmunológica mediada contra el desarrollo tumoral. Por ejemplo, se ha estudiado ampliamente al lipopolisacárido (LPS), que es un componente principal de la membrana externa en bacterias gramnegativas, el cual impulsa al receptor de la superficie celular del huésped (TLR4), perteneciente a la familia de receptores de reconocimiento de patrones (PRR), activando la respuesta mediada por células $\mathrm{T}$ inmunes contra las células cancerosas ${ }^{(43)}$.

Del mismo modo, el monofosforil lípido A (MPL) de la Salmonella entérica se ha utilizado actualmente como adyuvante en la formulación de la vacuna utilizada contra el carcinoma anticervical ${ }^{(44)}$. Por su parte, la piridoxina, una vitamina del complejo B producida por la acción bacteriana, puede activar la inmunovigilancia antitumoral del huésped.

En la revisión de Vivarelli y colaboradores se destacó el efecto prebiótico que tienen algunas bacterias comensales, lo cual protege al huésped contra la disbiosis intestinal o mejora la respuesta inmunitaria ${ }^{(45)}$. Ese es el caso de la combinación de Mutaflor ${ }^{\circledast}$ (E. coli, Nissle, 1917) con el antibiótico intestinal rifaximina, que evidenció un efecto antiinflamatorio de este antibiótico en un estudio en ratas con EII. Cabe resaltar que muchos probióticos han demostrado una posible actividad anti- 
neoplásica. En estudios realizados con ratones se los ha asociado con una inhibición del crecimiento de células tumorales. De acuerdo con lo reportado por Konishi y colaboradores, sobre el metabolito ferricromo secretado por el Lactobacillus casei, el cual puede desencadenar la apoptosis en las células tumorales por medio de la activación de la vía de la cinasa NH2-terminal de c-Jun $(\mathrm{JNK})^{(46)}$. Así, los lactobacilos también se han asociado con la estimulación de la inmunidad del huésped a través de las células asesinas naturales (NK), las células dendríticas (CD) o la respuesta de los linfocitos T helper 1 (TH1), lo que a su vez conduce a la eliminación de células cancerosas o precancerosas ${ }^{(47)}$.

En la Tabla 3 se resume lo expuesto en relación con el efecto de la microbiota intestinal sobre la prevención en desarrollo de tumores.

\section{EVIDENCIA QUE RELACIONA EL MICROBIOMA INTESTINAL CON LA INMUNOTERAPIA EN CÁNCER}

Múltiples estudios respaldan que los microbios intestinales pueden influir profundamente en la potencia de la inmunoterapia y algunas quimioterapias con funciones inmunoestimuladoras ${ }^{(4)}$. El trabajo pionero en este campo descubrió que la microbiota intestinal era esencial para las respuestas óptimas a la inmunoterapia con oligonucleótidos $\mathrm{CpG}$, que activa las células inmunes innatas a través de receptores tipo Toll-9 (TLR9). De manera similar, se descubrió que la microbiota intestinal da forma a la respuesta inmunitaria anticancerígena al estimular la generación de un subconjunto específico de linfocitos T helper 17 "patógenas" (pTH17) y la respuesta inmunitaria de los TH1 de memoria después del tratamiento con quimioterapia de inmunoestimulación con ciclofosfamida, esta evidencia asocia el microbioma intestinal con la inmunoterapia en cáncer ${ }^{(48)}$.
Ciertos taxones bacterianos en pacientes con neoplasias hematológicas están asociados con la eficacia del trasplante alogénico de células madre hematopoyéticas (alo-HSCT) y la disminución del riesgo de enfermedad de injerto contra huésped (EICH) después del tratamiento ${ }^{(49)}$.

\section{USO DE PROBIÓTICOS EN ONCOLOGÍA}

Varios estudios preclínicos y ensayos clínicos se han dirigido a evaluar la eficacia general de los probióticos en la reducción del riesgo y la gravedad de los efectos colaterales de los tratamientos para el cáncer, como diarrea y mucositis ${ }^{(50)}$.

El objetivo de administrar probióticos a pacientes con cáncer, principalmente lactobacilos, es repoblar la microbiota intestinal de los pacientes comprometidos, restableciendo así los niveles y la funcionalidad de las bacterias comensales, agotadas después de los tratamien$\operatorname{tos}^{(51)}$. Aunque los probióticos generalmente se consideran seguros, las principales preocupaciones de administrarlos a pacientes con cáncer inmunocomprometidos son tanto el riesgo potencial de desarrollo de infección oportunista como la transferencia de resistencia a los antibióticos. A pesar de los efectos benéficos observados con la administración de probióticos, se necesitan ensayos clínicos más grandes y controlados para respaldar la eficacia y seguridad de administrar especies seleccionadas de probióticos durante o después de tratamientos contra el cáncer ${ }^{(52)}$.

\section{CONCLUSIONES}

Sin duda, la microbiota intestinal es una comunidad compleja que tiene un rol preponderante en la salud de los seres humanos; es un sello personal de cada individuo, que se desarrolla con la edad y se modifica por medio de factores ambientales.

Tabla 3. Efectos antitumorales de la microbiota intestinal

\begin{tabular}{|l|l|l|l|l|l|l|}
\hline Microorganismos & Propioni bacteria & $\begin{array}{l}\text { Salmonella } \\
\text { enterica }\end{array}$ & L.casei & Gut bacteria spp & $\begin{array}{l}\text { Bacterias } \\
\text { gramnegativas }\end{array}$ & Lactobacillus spp \\
\hline Efectores & $\begin{array}{l}\text { Butirato } \\
\text { propionato }\end{array}$ & MPL & Ferricromo & Piridoxina & LPS & Desconocido \\
\hline Efectos & $\begin{array}{l}\text { Inhibición de las } \\
\text { desacetilasas de } \\
\text { histonas }\end{array}$ & $\begin{array}{l}\text { Utilizado como } \\
\text { adyuvante } \\
\text { en vacunas } \\
\text { anticáncer }\end{array}$ & $\begin{array}{l}\text { Detona la } \\
\text { apoptosis en } \\
\text { las células } \\
\text { cancerosas }\end{array}$ & $\begin{array}{l}\text { Activación de la } \\
\text { Rp inmunológica } \\
\text { contra el cáncer }\end{array}$ & $\begin{array}{l}\text { Activación } \\
\text { de la Rp } \\
\text { inmunológica } \\
\text { contra el cáncer }\end{array}$ & $\begin{array}{l}\text { Activación de la } \\
\text { Rp inmunológica } \\
\text { contra el cáncer }\end{array}$ \\
\hline
\end{tabular}

Rp: respuesta. Modificado de ${ }^{(43)}$. 
Existen diversos factores que predisponen al desarrollo del cáncer. Es por ello que resulta fundamental para su prevención establecer hábitos alimentarios y estilos de vida saludable, lo cual va a impactar directamente en la microbiota intestinal $y$, por ende, en el sistema inmunitario. Debe considerarse que irrespetar y agredir el medio donde se desarrolla la microbiota puede verse asociado con disbiosis, que se ha considerado que guarda nexos con el desarrollo de tumores. Como parte de la microbiota, hay elementos como el Lactobacillus $G G$, que ha demostrado tener un efecto benéfico en el tratamiento de la disbiosis. También es necesario resaltar que la microbiota se ha asociado con un efecto supresor del crecimiento tumoral e inmunoestimulador. Sin embargo, aún se necesitan estudios más profundos para analizar la posibilidad de considerarlo a futuro como adyuvante de las terapias anticáncer.

Indudablemente, se requieren de estudios de corte longitudinal de mayor envergadura para avanzar en los conocimientos sobre el tema.

\section{Financiación}

Los autores no recibieron ningún apoyo financiero para la investigación, autoría o publicación de este artículo.

\section{Conflicto de intereses}

Los autores declaran no tener conflictos de interés en la investigación, autoría o publicación de este artículo.

\section{Declaración de autoría}

DR, EFT realizaron la revisión bibliográfica y estructura de la revisión. DR, EFT escribieron el artículo. EFT realizó una revisión crítica del trabajo. Todos los autores leyeron y aprobaron el manuscrito final.

\section{Referencias bibliográficas}

1. Korecka A, Arulampalam V. The gut microbiome: scourge, sentinel or spectator? J Oral Microbiol. 2012;4:9367. doi: 10.3402/jom.v4i0.9367.

2. Brandi G, Frega G. Microbiota: Overview and Implication in Immunotherapy-Based Cancer Treatments. Int J Mol Sci. 2019;20(11):2699. doi: 10.3390/ijms20112699.

3. Whitman WB, Coleman DC, Wiebe WJ. Prokaryotes: the unseen majority. Proc Natl Acad Sci USA. 1998;95(12):657883. doi: 10.1073 /pnas.95.12.6578.

4. Global Burden of Disease Cancer Collaboration, Fitzmaurice C, Allen C, Barber RM, Barregard L, Bhutta ZA, et al. Global, regional, and national cancer incidence, mortality, years of life lost, years lived with disability, and disability-adjusted life-years for 32 cancer groups, 1990 to 2015: A systematic analysis for the global burden of disease study. JAMA Oncol. 2017;3(4):524-48. doi: 10.1001/jamaoncol.2016.5688.

5. Ashford NA, Bauman P, Brown HS, Clapp RW, Finkel AM, Gee D, et al. Cancer risk: Role of environment. Science. 2015;347(6223):727. doi: 10.1126/science.aaa6246.

6. Zhang Y-J, Li S, Gan R-Y, Zhou T, Xu D-P, Li H-B. Impacts of gut bacteria on human health and diseases. Int J Mol Sci. 2015;16(4):7493-519. doi: 10.3390/ijms16047493.

7. Goodman B, Gardner H. The microbiome and cancer. J Pathol. 2018;244(5):667-76. doi: 10.1002/path.5047.

8. Icaza-Chávez ME. Microbiota intestinal en la salud y la enfermedad. Rev. Gastroenterol. Méx. 2013;78(4):240-8. doi: 10.1016/j.rgmx.2013.04.004.

9. Feng Q, Chen W-D, Wang Y-D. Gut Microbiota: An Integral Moderator in Health and Disease. Front Microbiol. 2018;9:151. doi: 10.3389/fmicb.2018.00151.

10. Tao J, Li S, Gan R-Y, Zhao C-N, Meng X, Li H-B. Targeting gut microbiota with dietary components on cancer: Effects and potential mechanisms of action. Crit Rev Food Sci Nutr. 2020;60(6):1025-37. doi: 10.1080/10408398.2018.1555789.

11. Scott AJ, Alexander JL, Merrifield CA, Cunningham D, Jobin C, Brown R, et al. International Cancer Microbiome Consortium consensus statement on the role of the human microbiome in carcinogenesis. Gut. 2019;68(9):1624-32. doi: 10.1136/gutjnl-2019-318556.

12. Palmer C, Bik EM, DiGiulio DB, Relman DA, Brown PO. Development of the human infant intestinal microbiota. PLoS Biol. 2007;5(7):e177. doi: 10.1371/journal.pbio.0050177.

13. De Filippo C, Cavalieri D, Di Paola M, Ramazzotti M, Poullet JB, Massart S, et al. Impact of diet in shaping gut microbiota revealed by a comparative study in children from Europe and rural Africa. Proc Natl Acad Sci USA. 2010;107(33):14691-6. doi: 10.1073/pnas.1005963107.

14. Dominguez-Bello MG, Costello EK, Contreras M, Magris M, Hidalgo G, Fierer N, et al. Delivery mode shapes the acquisition and structure of the initial microbiota across multiple body habitats in newborns. Proc Natl Acad Sci USA. 2010;107(26):11971-5. doi: 10.1073/pnas.1002601107.

15. DuPont AW, DuPont HL. The intestinal microbiota and chronic disorders of the gut. Nat Rev Gastroenterol Hepatol. 2011;8(9):523-31. doi:10.1038/nrgastro.2011.133.

16. Magne F, Puchi SA, Carvajal B, Gotteland M. The elevated rate of cesarean section and its contribution to non-communicable chronic diseases in Latin America: The growing involvement of the microbiota. Front Pediatr. 2017;5:192. doi: 10.3389/ fped.2017.00192.

17. Dumas ME, Barton RH, Toye A, Cloarec O, Blancher C, Rothwell A, et al. Metabolic profiling reveals a contribution of gut microbiota to fatty liver phenotype in insulin-resistant mice. Proc Natl Acad Sci USA. 2006;103(33):12511-6. doi: 10.1073/pnas.0601056103. 
18. Vaishnava S, Behrendt CL, Ismail AS, Eckmann L, Hooper LV. Paneth cells directly sense gut commensals and maintain homeostasis at the intestinal host-microbial interface. Proc Natl Acad Sci USA. 2008;105(52):20858-63. doi: 10.1073/ pnas.0808723105.

19. Pereira ICMDS, Ferreira RK, Midori CP, Caldas FLF, Darrieux M, Manzano PT. Childhood obesity and Firmicutes/ Bacteroidetes ratio in the gut microbiota: a systematic review. Child Obes. 2018;14(8):501-9. doi: 10.1089/chi.2018.0040.

20. Muscogiuri G, Cantone E, Cassarano S, Tuccinardi D, Barrea L, Savastano S, et al. Gut microbiota: a new path to treat obesity. Int J Obes Suppl. 2019;9(1):10-9. doi: 10.1038/s41367019-0011-7.

21. Ley RE, Hamady M, Lozupone C, Turnbaugh PJ, Roy RR, Bircher JS, et al. Evolution of mammals and their gut microbes. Science. 2008;320(5883):1647-51. doi: 10.1126/ science.1155725.

22. Carding S, Verbeke K, Vipond DT, Corfe BM, Owen LJ. Dysbiosis of the gut microbiota in disease. Microb Ecol Health Dis. 2015;26:26191. doi: 10.3402/mehd.v26.26191.

23. Carabotti M, Scirocco A, Maselli M, Severi C. The gut-brain axis: Interactions between enteric microbiota, central and enteric nervous systems. Ann Gastroenterol. 2015;28(2):203-9.

24. Neuman H, Debelius JW, Knight R, Koren O. Microbial endocrinology: the interplay between the microbiota and the endocrine system. FEMS Microbiol Rev. 2015;39(4):509-21. doi: 10.1093/femsre/fuu010.

25. Sandrini S, Aldriwesh M, Alruways M, Freestone P. Microbial endocrinology: host-bacteria communication within the gut microbiome. J Endocrinol. 2015;225(2):R21-R34. doi: 10.1530/JOE-14-0615.

26. Queipo-Ortuño MI, Seoane LM, Murri M, Pardo M, GomezZumaquero JM, Cardona F, et al. Gut microbiota composition in male rat models under different nutritional status and physical activity and its association with serum leptin and ghrelin levels. PLoS One. 2013;8(5):e65465. doi: 10.1371/journal. pone.0065465.

27. Virchow R. An address on the value of pathological experiments. Br Med J. 1881;2(1075):198-203. doi: 10.1136/ bmj.2.1075.198.

28. Salim SY, Soderholm JD. Importance of disrupted intestinal barrier in inflammatory bowel diseases. Inflamm Bowel Dis. 2011;17(1):362-81. doi: 10.1002/ibd.21403.

29. Rodríguez D, Frias-Toral E, Santana S. Adjusted requirements for malnutrition of the cancer patient. Rev Oncol Ecu. 2019;29(2):83-96. doi: 10.33821/92.

30. Grivennikov SI, Greten FR, Karin M. Immunity, inflammation, and cancer. Cell. 2010;140(6):883-99. doi: 10.1016/j. cell.2010.01.025.

31. Zitvogel L, Galluzzi L, Viaud S, Vétizou M, Daillère, Merad $\mathrm{M}$, et al. Cancer and the gut microbiota: An unexpected link. Sci Transl Med. 2015;7(271):271ps1. doi: 10.1126/scitranslmed.3010473.
32. Wang J-L, Chang C-H, Lin J-W, Wu L-C, Chuang L-M, Lai M-S. Infection, antibiotic therapy and risk of colorectal cancer: A nationwide nested case-control study in patients with Type 2 diabetes mellitus. Int J Cancer. 2014;135(4):956-67. doi: $10.1002 / \mathrm{ijc} .28738$.

33. Bonnet M, Buc E, Sauvanet P, Darcha C, Dubois D, Pereira $\mathrm{B}$, et al. Colonization of the human gut by E. coli and colorectal cancer risk. Clin Cancer Res. 2014;20(4):859-67. doi: 10.1158/1078-0432.CCR-13-1343.

34. Davila A-M, Blachier F, Gotteland M, Andriamihaja M, Benetti P-H, Sanz Y, et al. Intestinal luminal nitrogen metabolism: role of the gut microbiota and consequences for the host. Pharmacol Res. 2013;68(1):95-107. doi: 10.1016/j. phrs.2012.11.005.

35. Yoshimoto S, Mun LT, Atarashi K, Kanda H, Sato S, Oyadomari S, et al. Obesity-induced gut microbial metabolite promotes liver cancer through senescence secretome. Nature. 2013;499(7456):97-101. doi: 10.1038/nature12347.

36. Rea D, Coppola G, Palma G, Barbieri A, Luciano A, Del Prete P, et al. Microbiota effects on cancer: From risks to therapies. Oncotarget. 2018;9(25):17915-27. doi: 10.18632/oncotarget.24681.

37. Sheflin AM, Whitney AK, Weir TL. Cancer-promoting effects of microbial dysbiosis. Curr Oncol Rep. 2014;16(10):406. doi: 10.1007/s11912-014-0406-0.

38. Bhatt AP, Redinbo MR, Bultman SJ. The role of the microbiome in cancer development and therapy. CA Cancer J Clin. 2017;67(4):326-44. doi: 10.3322/caac.21398.

39. Halazonetis TD. Constitutively active DNA damage checkpoint pathways as the driving force for the high frequency of p53 mutations in human cancer. DNA Repair. 2004;3(89):1057-62. doi: 10.1016/j.dnarep.2004.03.036.

40. Lara-Tejero M, Galán JE. A bacterial toxin that controls cell cycle progression as a deoxyribonuclease I-likeprotein. Science. 2000;290(5490):354-7. doi: 10.1126/science.290.5490.354.

41. Bergounioux J, Elisee R, Prunier A-L, Donnadieu F, Sperandio B, Sansonetti P, et al. Calpain activation by the Shigella flexneri effector VirA regulates key steps in the formation and life of the bacterium's epithelial niche. Cell Host Microbe. 2012;11(3):240-52. doi: 10.1016/j.chom.2012.01.013.

42. Jan G, Belzacq A, Haouzi D, Rouault A, Métivier D, Kroemer $G$, et al. Propionibacteria induce apoptosis of colorectal carcinoma cells via short-chain fatty acids acting on mitochondria. Cell Death Differ. 2002;9(2):179-88. doi: 10.1038/ sj.cdd. 4400935 .

43. Paulos CM, Wrzesinski C, Kaiser A, Hinrichs CS, Chieppa $\mathrm{M}$, Cassard L, et al. Microbial translocation augments the function of adoptively transferredself/tumor-specific CD8+ T cells via TLR4 signaling. J Clin Investig. 2007;117(8):2197204. doi: 10.1172/JCI32205.

44. Paavonen J, Naud P, Salmerón J, Wheeler CM, Chow S-N, Apter D, et al. Efficacy of human papillomavirus (HPV)16/18 AS04-adjuvanted vaccine against cervical infection 
and precancer caused by oncogenic HPV types (PATRICIA): final analysis of adouble-blind, randomised study in young women. Lancet. 2009;374(9686):301-14. doi: 10.1016/ S0140-6736(09)61248-4.

45. Vivarelli S, Salemi R, Candido S, Falzone L, Santagati M, Stefani S, et al. Gut microbiota and cancer from pathogenesis to therapy. Cancers. 2019;11(1):38. doi: 10.3390/cancers 11010038 .

46. Konishi H, Fujiya M, Tanaka H, Ueno N, Moriichi K, Sasajima $\mathrm{J}$, et al. Probiotic-derived ferrichrome inhibits colon cancer progression via JNK-mediated apoptosis. Nat Commun. 2016;7:12365. doi: 10.1038/ncomms 12365 .

47. Lenoir M, Del Carmen S, Cortes-Perez N, Lozano-Ojalvo D, Muñoz-Provencio D, Chain F, et al. Lactobacillus casei BL23 regulates Treg and Th17 T-cell populations and reduces DMH-associated colorectal cancer. J Gastroenterol. 2016;51(9):862-73. doi: 10.1007/s00535-015-1158-9.

48. Iida N, Dzutsev A, Stewart CA, Smith L, Bouladoux N, Weingarten RA, et al. Commensal bacteria control cancer response to therapy by modulating the tumor microenvironment. Science. 2013;342(6161):967-70. doi: 10.1126/ science. 1240527.

49. Jenq RR, Taur Y, Devlin SM, Ponce DM, Goldberg JD, Ahr $\mathrm{KF}$, et al. Intestinal Blautia is associated with reduced death from graft-versus-host disease. Biol Blood Marrow Transplant. 2015;21(8):1373-83. doi: 10.1016/j.bbmt.2015.04.016.

50. Lu D, Yan J, Liu F, Ding P, Chen B, Lu Y, et al. Probiotics in preventing and treating chemotherapy-induced diarrhea: A meta-analysis. Asia Pac J Clin Nutr. 2019;28(4):701-10. doi: 10.6133/apjen.201912_28(4).0005.

51. Zitvogel L, Ma Y, Raoult D, Kroemer G, Gajewski TF. The microbiome in cancer immunotherapy: Diagnostic tools and therapeutic strategies. Science. 2018;359(6382):1366-70. doi: 10.1126/science.aar6918.

52. Nagano T, Otoshi T, Hazama D, Kiriu T, Umezawa K, Katsurada N, et al. Novel cancer therapy targeting microbiome. Onco Targets Ther. 2019;12:3619-24. doi: 10.2147/ OTT.S207546. 